\title{
DEVELOPMENT OF SMART WELL UNITS FOR MULTILAYER RESERVOIRS OPERATED WITH THE SYSTEM OF SIMULTANOUS-SEPRATE EXPLOITATION
}

\author{
Lushpeev Vladimir Aleksandrovich ${ }^{1 *}$, Khmelenko Polina Pavlovna ${ }^{1}$, Tsiku lurii Kimovich ${ }^{2}$, \\ Tananykhin Dmitrii Sergeevich ${ }^{1}$ \\ ${ }^{1}$ Saint-Petersburg Mining University, Saint-Petersburg, Russian Federation \\ ${ }^{2} \mathrm{OAO}$ «Surgutneftegas», Surgut, Russian Federation
}

The paper shows a new approach to oilfields development. The advantages of multilayer reservoir facilities equipped with the system of simultaneous-separate exploitation are presented. New units are suggested to be applied in order to correspond the whole range of possibilities in the sphere of «smart wells». The devised fluid choking device allows changing flow characteristics without interfering in a borehole while the usage of simultaneous-separate exploitation facility allows monitoring the development of each individual layer witihin a multilayer object.

Key words: Completion; Multilayer; Reservoirs

\section{INTRODUCTION}

Nowadays the majority of mature oil fields in Russia are multilayer reservoirs with complex geological structure. Petroleum reserves tend to have deterioration [07].

In case of drilling each object of a multilayer deposit with an independent well pattern, there is an increase in the capital costs of drilling and the loss of total flow rate by 20-40 \% [06]. It may be possible to combine layers and to operate them using one well pattern [09]. However in this case layers should have the same reservoir pressure, that do not cause inter-formational flows, formation temperatures, porosity and permeability properties and water cut. Simultaneous-separateexploitation is used if these conditions are not met, and in order to decrease drilling and field facilities construction costs during the development of the multilayer reservoirs. The technology is based on the operation of two or more oil layers with an individualwell that has various spaces for transportation of reservoir products on independent (or joint) channels to the surface. Also, it fulfills an important requirement of the Regulation of oil fields development: monitoring the development of each individual layer witihin a multilayer object [05].According to SPE International the advanced high-technology simultaneous-separate exploitation for multilayer reservoirs is becoming increasingly popular. There are a lot of modifications of simultaneous-separate exploitation for oil and gas industry, that are used according to geologic and technical conditions and well-producing characteristics. For example, layers can be isolated using packers, and the well can have one or more pipe rows, that have a concentric or parallel location [01].

State requirements on efficient reservoirs development and the will of oil companies to increase oil recovery factor and to reduce production costs led to the development of «smart wells» for multilayer reservoirs [08].

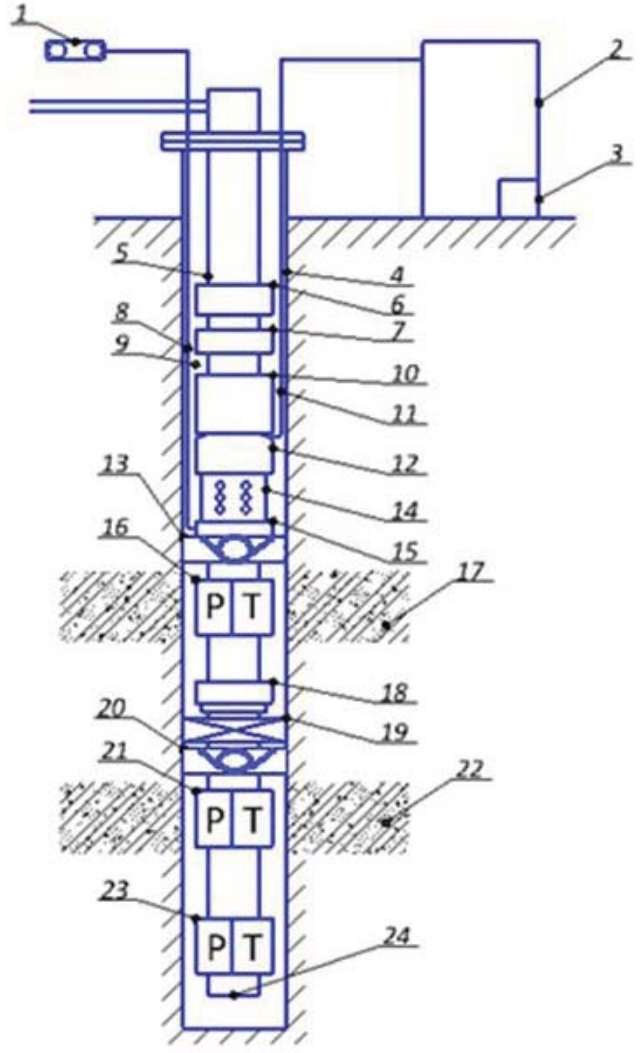

Figure 1: Installation scheme:

1 - control station for electric controlled shut-off valve, 2 - control station, 3 - receiver-processor unit, 4 - borehole, 5 - tubing string, 6 - drain valve, 7 - non-return valve, 8 - power cable for shut-off valve, 9 - annulus, 10 -pump, 11 - power cable for electric submersible motor, 12 - electric submersible motor (ESM), 13, 20 - produced fluids choking devices, 14 - telemechanics unit, 15 - electric controlled shut-off valve, 16,21,23 pressure and temperature sensors, 17,22 - formations, 18 - isolating switch, 19 - packer, 24 - production liner 
Intelligent systems and a full range of complex technical facilities issued by such major companies as Halliburton, Baker OilTools, Weatherford, and others were created to realize such good control practices.

Despite the wide range of technical facilities, the whole control complex for multilayer field development practice is used rarely. At the same time characteristics, all-around monitoring allows taking decisions on time, control and keeping up reservoir pressure, which leads to increase: oil recovery factor, economic efficiency and industrial safety. Thus oil companies that use standard constructions of simultaneous-separate exploitation technology, without smart monitoring systems, do not have the better understanding of many development features of certain zones within multilayer reservoirs. In order to handle the allocation metering during simultaneous-separate exploitation and to correspond the whole possibility range in the sphere of «smart wells» the following units are suggested to be applied (Figure 1):

- Measurement and register devices

- Electric controlled valve

- Produced fluids choking device for each formation

- Packer and anchor equipment for formation isolation

- Isolating switch for packer fixing and its removal

- Control station with embedded software for ESP and valves joint action

\section{MEASUREMENT AND REGISTER DEVICES PLACED DIRECTLY IN THE WELL}

In order to register operational parameters of the well, like pressure and temperature measurement, remote and local monitoring sensors are used.

Fluid level are used for determination of bottom-hole pressure according to the depth of interface level of fluid column. However it should be mentioned that different factors influence the quality of sound speed estimation: skim oil formations, the estimation error of the tubing average length, borehole axis curvature, paraffin deposits on the pipe joint, pressure, temperature and density of petroleum gas, all this factors lead to quality estimation decrease. Measurement error of fluid level in casing annulus can rise up to $20 \%$.

It is suggested to eliminate disadvantages by installing pressure and temperature sensors next toevery layer and in the sump. Received data can be transmitted to the data receiving and processing unit (telemechanics unit). This arrangement allows performing flow measurement and well tests.

OAO «Surgutneftegas», that owns large oil and gas reserves in Western Siberia, use the technology of thermohydrodynamics investigations of multilayer anisotropic formations for current production rate test. Temperature registration takes place during adiabatic expansion (compression), and then - thermal pressure treatment (processing) effect of expanded fluid heating. It is found the- oretically and as an experimental fact, that temperature fluctuations occurring during the start-up of the oilfield development are in proportion to the filtration fluid rate of each layer[03]. The purpose of these measurements is determination of filtration parameters of every layer. Sensors output data is used for velocity measurement, and therefore formation flow rate. Summary diagrams of pressure and temperature change along a borehole are also can be given [03]. The company recorded data showed quality information about flow properties of the layer.

Pressure and temperature sensors can be used during steady-state and unsteady-state modes. The first one includes different reservoir drawdowns. The outcome of the registered pressures is well test-based cross-plot of drawdown vs flow rate. This cross-plot allows finding productivity index and formation conductivity. The unsteady-state mode involves construction pressure build-up curve (PBC). These two kinds of the well hydrodynamic researches can be combined in the case of multilayer object [05].

The received data after complex researches allows to control, manage and optimize the performance of the operated layers, and to plan and evaluate the effectiveness of geological and technical measures. This can be achieved in response to software support build in the ESP control panels [05].

\section{ELECTRIC CONTROLLED VALVES}

For formations operation monitoring purposes the control station supplies power to electric-controlled valve motor via the ESP motor power cable. This closes the tubing bore, pressure rises up to the actual formation pressure value of the lower reservoir. A pressure sensor installed in the electric valve transmits the pressure data to the receiving and processing unit. Then this information transmits to the well master control console.

Thus electric valve performs two functions: the first one is measuring the lower reservoir formation pressure during pump operation; the second one is shutting off the fluid flow from the lower reservoir. Technology pilot tests showed rapid time to value (about 6 months) and sufficiently high efficiency [04]. At the same time, OAO «Surgutneftegas» performed field-test facilities with electromagnetic shutdown valves. Valve control is processed by a constant voltage. It appeared that among the disadvantages are the usage of two power supply cables (for submersible electric motor and valve), this increases the risks of mechanic damages during round trip, leakage of cable entry after inspections [10]. This technology is counterproductive because the device can service only in two extreme positions, i.e. either «open» or «close».

It is suggested to develop fluids choking device that can regulate fluid flow in various intermediate positions. 


\section{CHOKING DEVICE FOR PRODUCED FLUID}

The presented complex differs from previously tested ones because it has a fluid choking device, in addition to electric valves, which creates different pressure drawdown on the operated layer. Each diameter of the device corresponds to the definite value of the pressure drawdown, that is set by variable speed drive of ESP. Reservoir production characteristics variety due to the change of the flow area of the tool. The control station supplies power to the valve via a power cable, then the device reduces its size in order to decrease the flow rate or drifts for enhancing production rate of the reservoir layer. The distinctive feature of this tool is a possibility of choking instead of cutting off fluid flow from each formation.

Steady-state mode well tests involve changing the size of the device, and the production as well, using temperature log with the received data from the sensors for managing.

The wells equipped with the described arrangement can be fully automated since the usage of the multi-sensor system for thermohydrodynamic wells tests and online data transmission to thecontrol station. Received data from the borehole bottom zone is being processed, interpreted into the hydrodynamic model and then the appropriate drawdown pressure is automatically calculated. Production condition of wells changes. Hence new production level can be achieved in a short span of time due to online data transmission, registered by subsurface sensors.

It is proved that such smart well operation allows changing flow characteristics without interfering in a borehole and potentially increases NPV on billion dollars [08].

\section{CUTTING OFF THE LAYERS}

For unsteady-state modestudies each of the layers is cut for recording high-quality build-up while pressure recovers. Howeverinterformational flows are common for multilayer reservoirs. Here for cutting off the layers electric valves are used. Providing qualitative valves sealing there wouldn't be producing formation impact on the pressure buildup measurement.

\section{DAMAGE OF THE BOTTOM HOLE FORMATION ZONE}

Bottom hole formation zone is a part of a formation hydrodynamic system, where the fluid flow comes amid with high velocity, pressure and temperature gradients and it is complicated by the fact of appearing fractured, nonuniform permeable zones, phase transitions [02].

During the well operation, the state of the bottom hole formation zone is continuously changing.

Formation contamination with borehole fluid particles, called clogging, takes place through the development phase. As the result, a new additional resistance appears and cause a decrease in productive capacity. This resistance is measured by the growth of the hydrodynamic parameter - skin factor. The skin factor value can be identified using pressure build-up curve, as the result of test at unsteady-state mode.

Fixing the damage ratio of each layer can be done using dynamic survey curve of steady-state mode (Figure 2). The decline of the line in the diagram will show the decrease of production rates of each layer and the whole production of the well.

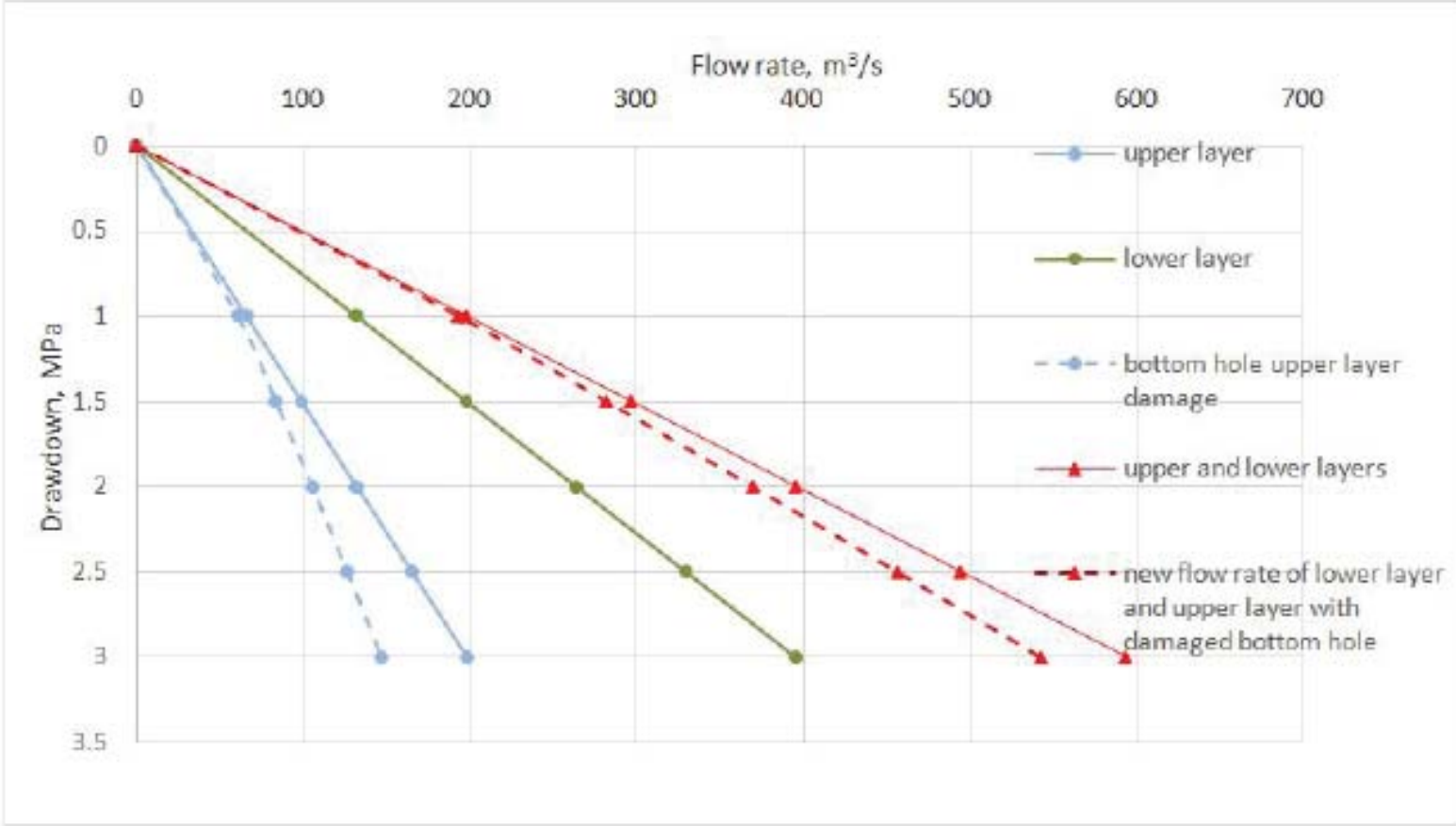

Figure 2: Production rate monitoring using dynamic survey curve of steady-state mode 
During the damage of the bottom hole formation zone, the pressure and temperature sensors transmit the data to telemechanics unit for the flow rate estimation by thermohydrodynamics tests.

The suggested tool will allow selecting the most suitable diameter of the chocking device automatically.

Having monitored the production rate decline in comparison to the initial value the auto select is being done for the build-up of drawdown for low permeability near the wellbore layer. At the same time, the diameter of this device near another layer is unchanged.

\section{CONCLUSIONS}

The proposed complex is recognized as an important to the goal of fulfilling a requirement of the Regulation of oil fields development: monitoring the development of each individual layer within a multilayer object and corresponding the full whole range of new possibilities in the sphere of «smart wells». The described measurement and register devices, electric controlled valve and produced fluids choking device for each formation allows to monitor the multilayer oil fields online, provide hydrodynamic researches, change the operating regimes, maintain a stable influx in case of increasing the skin factor and avoidance of interformational flows during cutting off one of the layers. Unlike most other inventionsthis complex has a choking device, that can change automatically its diameter and create a drawdown along with electric submersible pump at any of the layers.

The well equipped with such simultaneous-separate exploitation device fully compline with the definition of «smart well», because it allows changing the inflow online without the help of the operator. The complex finds the most appropriate diameter of flow area depending on the reservoir properties (formation pressure, skin factor, etc.), maintaining the uniform development and monitoring the process aswell.

\section{REFERENCES}

1. Abdulin, F.S. (1987). Production of Oil and Gas. Moscow: Mir Publishers.

2. Akhmetianov, I.R. (2016). Bottom hole formation zone damage during field development. Symbol of science, N. 7.. Retrieved from https://cyberleninka.ru/article/n/uhudshenie-svoystv-pzp-v-protsesse-razrabotki-mestorozhdeniya
3. Fedorov, V.N., \&Lushpeev, V.A. (2004). Modeling in processing and interpretations of thermohydrodynamic researches of wells. Oil industry, 12. pp. 100-102. Retrieved from http://www.oil-industry.net/ Journal/archive_detail.php?art=119767

4. Kostilevskii, V.A., Shamilov, F.T., \&Feofilaktov, S.V. (2017). Technology for formations productivity measurement during dual production with ESP by LUKOIL-Western Siberia LLC. Oil industry, N. 8., pp. 108-111, DOI: 10.24887/0028-2448-2017-8-108111. Retrieved from http://www.oil-industry.net/Journal/archive_detail.php?art=230630

5. Lushpeev, V.A., Kochetkov, L.M., Bastrikov, S.N., \&Fedorov, V.N. (2016). Multilayer well test technology of facilities equipped with the system of dual completion. Oil and Gas Territory, N. 2., pp. 76-80.. Retrieved from http://neftegas.info/tng/2-2016/tekhnologiya-issledovaniya-mnogoplastovykh-obektov-oborudovannykh-sistemoy-odnovremenno-razdelnoy-ek/?sphrase_id=24555

6. Nurgaliev, A.A., \&Khabibullin, L.T. (2016). Analysis of efficiency of simultaneous-separate well operation in the South-East of the Republic of Tatarstan. Interexpo Geo Siberia, Vol. 3, N. 2., pp. 230-233.. Retrieved from https://cyberleninka.ru/article/n/analiz-effektivnosti-odnovremenno-razdelnoy-ekspluatatsii-skvazhin-na-mestorozhdeniyah-yugo-vostoka-respubliki-tatarstan

7. Rogachev, M., \&Kondrashev, A. (2016). Substantiation of the technology of in-situ waterproofing in low-permeability reservoirs. In Proceedings of the Mining Institute. Retrieved from http://pmi.spmi.ru/ index.php/pmi/article/view/34

8. Sadykova, R.S., Abdullina, L.A., \&Gazizullina, L.I. (2013). Innovative technologies in oil industry: intellectual equipment of wells. Actual problems of economics and law, Vol. 2, N. 26., pp. 94-100. Retrieved from https://cyberleninka.ru/article/n/innovatsionnye-tehnologii-v-neftyanoy-promyshlennosti-intellektualnoe-osnaschenie-skvazhin

9. Tausch, G.H., \&Kenneday, J.W. (1956). Permanent-type Dual Completions. Drilling and Production Practice. Conference paper. Retrieved from https:// www.onepetro.org/

10. Tsiku, I.K., Popov, I.V., \&Tsepliaev, I.I. (2016). Experience of integration of new facilities at OJSC "Surgutneftegas" oilfields. Engineering practice, N. 5., pp. 30-34. Retrieved from https://glavteh.ru/

Paper submitted: 01.06.2018.

Paper accepted: 11.08.2018.

This is an open access article distributed under the CC BY-NC-ND 4.0 terms and conditions. 